\title{
Karpal Tünel Sendromunun Cerrahi Tedavisinde Sınırlı İnsizyon Uygulamalarımız
}

\section{Our Limited Incision Applications In The Surgical Treatment Of Carpal Tunnel Syndrome}

\author{
Anvar Ahmedov ${ }^{1 *}$ \\ ${ }^{1}$ Başakşehir Çam ve Sakura Şehir Hastanesi, İstanbul, Turkey. \\ e-mail: anvar.ahmedov@yahoo.com \\ ORCID: 0000-0002-5100-4672 \\ *Sorumlu yazar/ Corresponding Author: Anvar Ahmedov \\ Gönderim Tarihi / Received: 22.01.2021 \\ Kabul Tarihi / Accepted: 14.04.2021 \\ DOI: $10.34087 /$ cbusbed. 866345
}

\section{Öz}

Giriș ve Amaç: Klasik açık teknik ile yapılan karpal tünel ameliyatlarında, uygulanan insizyona bağlı olarak, ameliyat sonrası pilar bölgede ağrı ve hassasiyet, el bileğinde sertlik, palmar kütanöz dal kesilmesine bağlı nöroma şikayetleri görülmektedir. Ameliyat insizyonunun sınırlı tutularak, pilar bölgesinin belirli derecede korunduğu olgularda, bahsedilen şikayetlerin azaltılacağı düşündüğümüz için bu çalışma planlandı.

Gereç ve Yöntemler: 2010 Ocak -2011 Aralık tarihleri arasında kliniğimizde seçilmiş karpal tünel sendromu tanısı alan 40 hastaya, sınırlı insizyonla karpal tünel cerrahi tedavisi uygulandı. Hastalarda preoperatif EMG ile sinirlerin hasar derecesine bakıldı. Disabilities of the Arm, Shoulder and Hand-Türkçe semptom skorlaması (Quick DASH-T) ve Boston Karpal Tünel Sorgulama Anketi (BKTSA) kullanılarak hastalığın şiddeti ve üst ekstremitenin fonksiyonel durumu değerlendirildi. Tüm hastalarda Tinel ve Phalen testleri yapıldı.

Bulgular: Postoperatif dönemdeki takiplerde hastalar değerlendirildi. Pilar bölgesinde ağrı ve hasiyet hiçbir hastada görülmedi. Hiçbir hastada skar sertliği şikayeti ve nöroma gelişimine rastlanmadı. Tinel ve Phalen testlerinin postoperatif negatiflik oranı literatür verilerine yakın olarak hesaplandı. Quick DASH-T ve BKTSA sonuçları preoperatif sonuçlarla karşılaştırıldı ve istatistiksel olarak anlamlı bulundu. Literatür ve benzer yayınlarda değerlendirilmesi önerilen yüzeyel ark yaralanmasının tespiti amacıyla 5 kişilik randomize grup oluşturuldu. Yapılan ultrason incelemesinde hiçbir hastada yüzeyel palmar ark hasarına rastlanmadı.

Sonuç: Çalışmamız sonucunda, uygun olgularda sınırlı insizyon uygulanarak yapılan karpal tünel cerahisininin olumlu sonuçlar verdiği, özellikle mesleği gereği pilar bölgesine bası uygulanan olgularda tercih edilebilecek bir yöntem olabileceği kanaatine varıldı.

Anahtar kelimeler: Karpal tünel sendromu, Median sinir, Palmar kütanöz dal, Pilar bölge, Sınırlı insizyon.

Abstract
Objective: The type of incision made is very important in carpal tunnel surgery. The classic open technique in carpal
tunnel syndrome surgery leads to specific complaints of pain and tenderness in the pilar region, stiffness of the wrist,
and neuroma complaints when the palmar cutaneous branch has been cut during surgery. With the aim of reducing
these postoperative complaints, this study was planned to evaluate cases where a limited operation incision had been
made and the pilar region was protected to a certain extent.
Materials and Methods: Between January 2010 and December 2011,40 selected patients with carpal tunnel
syndrome were treated with limited incision carpal tunnel surgery in our clinic. The degree of nerve damage was
evaluated with preoperative EMG. The severity of the disease and the functional state of the upper limb was assessed
with the Disease of the Arm, Shoulder, and Hand Scale -Turkish version, and the Boston Carpal Tunnel Inquiry
Questionnaire. Tinel and Phalen tests were performed in all patients.
Results: In the postoperative follow-up examinations, no pain or sensitivity in the pilar region was determined in any
patient. No patient complained of scar stiffness and neuroma development. The postoperative negative rate of Tinel
and Phalen tests was close to findings in literature. A statistically significant improvement was determined in the


Quick DASH-T and BKTSA results from preoperative to postoperative. A group of 5 patients were selected at random for the detection of superficial artery arch injury, the evaluation of which has been recommended in the literature and similar publications. In the ultrasound examination, no superficial palmar artery arch damage was observed in any patient.

Conclusion: From the results of this study, it was concluded that carpal tunnel surgery applied with a limited incision in appropriate cases, provides positive results. This method could be preferred especially in cases where there is greater pressure on the pilar region required by their profession.

Keywords: Carpal tunnel syndrome, Limited incision, Median nerve, Palmar cutaneous branch, Pilar region.

\begin{abstract}
1. Giriş
Karpal tünel sendromu en s1k görülen periferik tuzak nöropatisidir. Karpal tünel sendromu, median sinirin karpal tünel içerisinde sıkışmasıyla gelişen, periferik tuzak nöropati sonrası, ellerde uyuşma, hissizlik, karıncalanma ve ağrı gibi şikayetlerle başlar. Hastalığın son evrelerinde ise geri dönüşü olmayan periferik sinir hasarına bağlı olarak başparmak oppozisyonunun kaybı, buna bağlı olarak başparmak kavrama gücünün azalması ve ciddi motor fonksiyon kaybı gelişir [1].
\end{abstract}

Günümüzde karpal tünel sendromu farklı cerrahi tekniklerle tedavi edilmektedir:

Karpal Tunel Sendronunun tedavisinde uygulanan klasik açık ameliyat tekniği: Distalde Kaplan'ın kardinal çizgisinin tenar krizi kestiği yerin 4-6 mm ulnar bölgesinden başlayarak, tenar krize paralel olacak şekilde proksimalde distal bilek krizine kadar uzanan curvilinear insizyon sonrası, distal bilek krizinden 45 derecelik açı yaparak proksimale ve ulnara doğru, yaklaşık $1,5 \mathrm{~cm}$ uzunluğunda ikinci insizyon yapılır. Fleksör karpal retinakulumun açılması, antebrakial ve palmar fasyaların kesilmesi ile median sinir serbestleştirilir. $\mathrm{Bu}$ yöntem median sinirin (eksternal ve internal) nörolizine, karpal tünel içinin olası ek lezyonlar (ganglion, kist vb.) açısından kontrol edilmesine, sinovial hipertrofi varsa sinovyektomi yapılmasına imkan veren bir tekniktir. Postoperatif dönemde, cerrahi insizyonun uzun olması, pilar bölgede ağrı ve hassasiyetin oluşması, uzun skar sebebiyle sertlik oluşması, palmar kütanöz dal kesilirse nöroma oluşması gibi sorunlar tekniğin belli başlı komplikasyonlarını oluşturur [1,2].

Sınırlı insizyon ile ameliyat tekniği: Distal el bileği krizinin 1- 1,5 cm distalinden başlayan insizyon, tenar kriz 2 mm unlarından, krize paralel olarak devam eder ve Kaplan'ın kardinal çizgisine kadar uzanır. Karpal tünel, fleksör karpal retinakulum distali kesilerek açılır ve median sinir ortaya konur. Bölgenin proksimalinde fleksör retinakulum proksimali ve antebrakiyal fasya, retinakulum üzerinden yapılan disseksiyonla ortaya konur ve alttaki yapıların görülerek korunmasıyla kesilerek açılır. Median sinir nörolizi, karpal kanal içinin eksplorasyonu, sinovektomi yapılır ve serçe parmakla fleksör retinakulum, antebrakiyal fasya ligamanlarının iyice gevşetilip gevşetilmediği kontrol edilir [2].

Sınırlı insizyon cerrahi tekniği ile, pilar bölgesinin korunabileceği, özellikle pilar bölgede rastlanılan ağrı ve hassasiyet gibi bazı komplikasyonların azaltılabileceği düşünülmektedir [2].

Karpal tünel sendromu cerrahi tedavisinin altın standart yöntemi, açık klasik cerrahi tedavi yöntemidir. Her yöntemin olduğu gibi, bu yöntemin de belli oranda komplikasyonları mevcuttur. Karpal tünel sendromunun

klasik açı teknik ile cerrahi tedavisinin komplikasyonları arasında yer alan pilar bölgesinde ağrı ve/veya hassasiyet oluşması ve uzun skar sebebiyle sertlik gelişmesinin önüne geçilmesi için insizyonun daha kısa tutularak pilar bölgesinin korunması etkili olabilmektedir. Bu çalışmada el bileğinin pilar bölgesi korunarak 2,5 cm'lik sınırlı insizyonla yapılan karpal tünel sendromu cerrahisinin komplikasyon, cerrahi alan açıklığı ve disseksiyon imkanı açısından değerlendirilmesi amaçlandı.

Bazı araştırmacılar açık cerrahide insizyon tipi ile komplikasyonlar arasında ilişki olduğunu açıklamışlardır. Standart insizyonla yapılan cerrahi sağaltımlarda fleksör tendonlarda gerginlik, aşırı skar dokusu oluşumu, duyarlılıkta artış gibi komplikasyonların oluşabileceği vurgulanmıştır. Das ve Brown 170 vakalı serilerinde operasyon sonras1 erkenden mobilizasyona izin verdikleri halde sinir ve tendonların prolapsusu veya sinirin skar dokusunda sıkışması gibi komplikasyonlarla karşılaşmadıklarını açıklamışlardır [3]. Broomley KTS dekompresyonu için mini insizyon tekniğini uygulamış ve bu yöntem ile daha küçük skar dokusu oluştuğunu, lokal anestezi ile yapılabildiğini, operasyon zamanının çok kısa olduğunu ve postoperatif rahatsızlıkların daha az görüldüğünü bildirmiştir. Lee ve Strickland sınırlandırılmış palmar insizyon tekniği ile yapmış oldukları operasyonlar sonrasında hastalarının şikayetlerinin \% 92 oranında tamamen geçtiğini ya da minimal olduğunu saptamışlardır. Karakurum ve arkadaşları minipalmar insizyonla yaptıkları KTS operasyonu sonucunda Lee'nin çalışmasına benzer şekilde \% 91 oranında etkili sonuçlar elde ettiklerini belirtmişlerdir. Ziyal ve arkadaşları yaptıkları araştırmada standart insizyonla sağaltılan olguların üçünde bilek hareketlerinde rahatsılık hissi bulmuşlardır. Otörler, serilerinde ise dönüş süresini standart insizyonda 4 hafta ve küçük insizyonda ise 3 hafta olarak saptamışlardır. Shapiro ise mikrocerrahi ile karpal tünel gevşetme adını verdiği operasyon sırasında bazen cerrahi mikroskop bazen de lup kullanarak mini insizyonla yaptığı serisinde \%96 oranında iyileşme olduğunu açıklamıştır [4].

\section{Materials ve Methods}

Çalışma, XXXXX Üniversitesi XXXXX Tıp Fakültesi Plastik, Rekonstruktif ve Estetik Cerrahi Anabilim Dalı'nda 1 Ocak 2010 ve 31 Aralık 2011 tarihleri arasında yapıldı. Araştırma için XXXXX Üniversitesi XXXXX Tıp Fakültesi Klinik Araştırmalar Etik Kurulu'ndan yazılı izin alındı. Çalışma Helsinki 
Deklerasyonu 2008 prensiplerine uygun olarak yapıld1. Bu dönemde, El Cerrahisi polikliniğine başvuran, karpal tünel sendromu tanısı konmuş, cerrahi tedavi endikasyonu olan ve hastalığı çok ileri evrede olmayan (Bland sinıflamasina göre; evre 2, 3 ve 4) ve daha önceden aynı sebepten dolayı ameliyat olmayan hastalar bu çalışmaya dahil edildi. Örneklem seçimi basit rastgele sayılar tablosu kullanılarak yapıldı. Çalışma grubundaki hastalar rastgele seçilmiş olup, yaş aralığ 38 ile 68 yaş olup hastaların yaş ortalaması $51 \pm 7$ idi. Bu çalışmaya sadece çalışmayı yürüten hekime başvuran hastalar dahil edildi. Tüm hastalarda anamnez, duyu ve motor değerlendirilmesi, Tinel ve Phalen testleri, preoperatif ve postoperatif EMG değerlendirilmesi yapıldı. Cerrahi hazırlığı eksiksiz tamamlanan hastalara anestezi muayenesi sonrası ameliyat planlaması yapıld1. Ameliyat tarihinden bir gün önce hastaların İstanbul Tıp Fakültesi Hastanesi Plastik, Rekonstruktif ve Estetik Cerrahi Kliniği'ne yatışı yapıldı. Aynı gün hastalar yatağında ziyaret edilerek operasyon planlanan eli işaretlendi, her hastaya çalışma ve yöntem hakkında detaylı bilgi verilerek aydınlatılmış onam formunun içeriği anlatıldı, onamları alındı. Quick-DASH-T ve BKTSA formları verilerek, operasyon planlanan elinin duyu ve motor fonksiyon değerlendirilmesi puan bazında yapıldı.

Çalıșma grubundaki hastaların hepsi rejionel anestezi altında ameliyat edildi, anksiyetesi yüksek hastalara, sakinleştirmek amacıyla Dormicum 1-2 mg intravenöz (iv) premedikasyon ve gerekli durumlarda peroperatif sedatif ilaç takviyesi anestezi ekibince yapıldı. Hastaların opere edileceği ekstremitesine kol turnikesi bağlanmasını takiben, poviiodeks (\%10 povidon-iyot) ile silinip steril örtüldü, çizim yapıldıktan sonra profilaktik antibiyotik (Sefazol 1 gr)iv olarak verildi.Ameliyat başlamadan önce, Esmarch bandajı yüzeyel venleri boşaltmak için sarıldı ve kol turnikesi şişirilmesini takiben turnike saati başlatıldı. Ameliyat süreleri ortalama 30-40 dakika kadar devam etti. Kanama kontrolü sadece cilt altı dokularına uygulandı, ardından halen sızdırmakta olan yaralar için penrose dren ameliyat ertesi sabahına kadar konarak cerrahi yara kapatıld1. Postoperatif pansuman sonras1, kliniğimizde rutin halde olan el bileğini nötral pozisyonda tutan, yarım alçı ateli uygulandı. Medikal tedavide; el elevasyonu, sefazol $1 \mathrm{~g}$ 4x1, oksamen-L flk. 1x1, perfalgan $500 \mathrm{mg}$ flk. 4x1, ranitab amp. 2x1 kullanıldı. Her hasta ameliyat olduğu günü hastanede geçirdi.

Hastalara ameliyat sonrası aksiller bloğun 4 ile 8 saat süreceği belirtilerek, diğer eliyle operasyon yapılan kolunun (istemli hareket yapamayacağından dolayı) desteklemesi vurguland1.

Postoperatif 1. gün sabahı, opere el pansumanı açılarak elin duyu ve fonksiyonu değerlendirildi; hematom, yara ayrışması ve enfeksiyon açısından kontrolü yapıldı. Ĕger uygulanmışsa; penrose dreni çıkartıldı, daha sonra pansuman yapılarak ateli tekrar yerleştirildi. Tüm hastalara, 3 gün arayla kliniğimiz el cerrahisi polikliniğinden takipleri yapıldı. Postoperatif 12. gün sütürleri alınan hastalar,21. gün için kontrole çağırıldı ve el bileği ateli çıkarılarak, el cerrahisi fizik tedavi ünitesine el rehabilitasyonu için sevk edildi.

Postoperatif takiplerde hastaların ameliyatla ilgili herhangi bir şikayeti olmadı. Ellerindeki karıncalanma ve uyuşma postoperatif 1 . haftada geriledi. Nokturnal paresteziden dolayı gece kalkma ve el sallama şikayetleri ortadan kalktı. Erken postoperatif dönemde, hiçbir hastada hematom ve enfeksiyon görülmedi.

Cerrahi yakın takip sonlandırıldıktan sonra hasta grubu postoperatif 6 . ile 9 . ayda kontrole çağrıldı ve ameliyattan sonraki iyileşme süreçlerinin nasıl geçtiği ve şikayetleri sorguland. BKTSA ve Quick DASH-T anketleri verilerek şikayetlerinin derecelerine göre doldurulmaları istendi, el muayeneleri yapıldı, provokasyon testleri (Tinel, Phalen) tekrar edildi. Hastalardan kontrol EMG tetkikleri istendi. Takip süresi en az 6 ay olan hastalar çalışmaya dahil edildi. İstatistiksel anlamlılık $\mathrm{p}<0,001$ düzeyinde değerlendirildi.Verilerin tanımlayıcı istatistikleri ortalama, standart sapma ve median, min, max ile belirtilmiş ve istatiksel analiz için Wilcoxon testi kullanılmıştır. Veriler SPSS V21.0 programı ile değerlendirildi.

\subsection{Cerrahi Teknik}

Hasta ameliyat masasına prone pozisyonunda yatacak şekilde alındı. Opere olacak tarafta el operasyon masası kullanıldı. Aksiller blok yapıldıktan sonra, cerrahi alan silindi ve steril örtüldü. Esmarch bandaj sarıldıktan sonra, pnömotik turnike 250-270 $\mathrm{mmHg}$ basincinda şişirildi. Distal bilek krizinden 1-1,5 cm distalde başlayan ve Kaplan kardinal çizgisine kadar tenar krizin $2 \mathrm{~mm}$ ulnarında kalacak şekilde krize paralel $2,5 \mathrm{~cm}$ insizyon yapıldı (Şekil 1).

Cilt ve cilt-altı dokusu geçildikten sonra, palmar fasya ve fleksör retinakulum insize edildi, daha sonra 15 nolu bisturiyle dikkatlice derinleşmeye devam edilerek, karpal kanala ulaşılınca koyu gri renkte sinovyum görüldü. Hemostatla alttaki yapılar fleksör retinakulumden ayrıldıktan sonra bisturiyle retinakulum distali gevşetildi. Metsenbaum makasıyla ciltaltı planda proksimale doğru vertikal düzlemde yapılan disseksiyon hareketleriyle fleksör retinakulum ve distal antebrakyal fasya yumuşak dokudan ayrılarak ciltaltı tünel oluşturuldu.

Catspow ekartörüyle cilt ve cilt altı eleve edilerek, hemostatla fleksör retinakulum altındaki yapılar ayrıldı, metsenbaum makasıyla dikkatlice retinakulum ve fasya, el masasının kendi tarafındaki uzak ucuna geçilerek ve hastanın kolu dirsekten hafif fleksiyona getirilerek (median sinir görülür), transvers karpal ligaman ve antebrakiyal fasya kesildi. Islatılmış sol el serçe parmağıyla, karpal tünel eksplorasyonu yapıldı ve önkol distalinin gevşetildiği iyice anlaşıldı.

Median sinir, etrafındaki sinovyumdan serbestleştirilerek askıya alındı ve median sinire eksternal nöröliz yapıldı. Sinire hafifçe distal traksiyon uygulanarak proksimal nöroliz ve proksimale traksiyon yapılarak distal nöroliz yapild1.

Median sinirin rekkürran dalı ortaya konarak nöroliz yapıldı. Sinovyal hipertrofi için sinovyektomi yapıldı. Turnike açılıp hemostaz sağlandı (sadece cilt altı planında). Yeterli hemostazın sağlanamadığı olgularda 1 

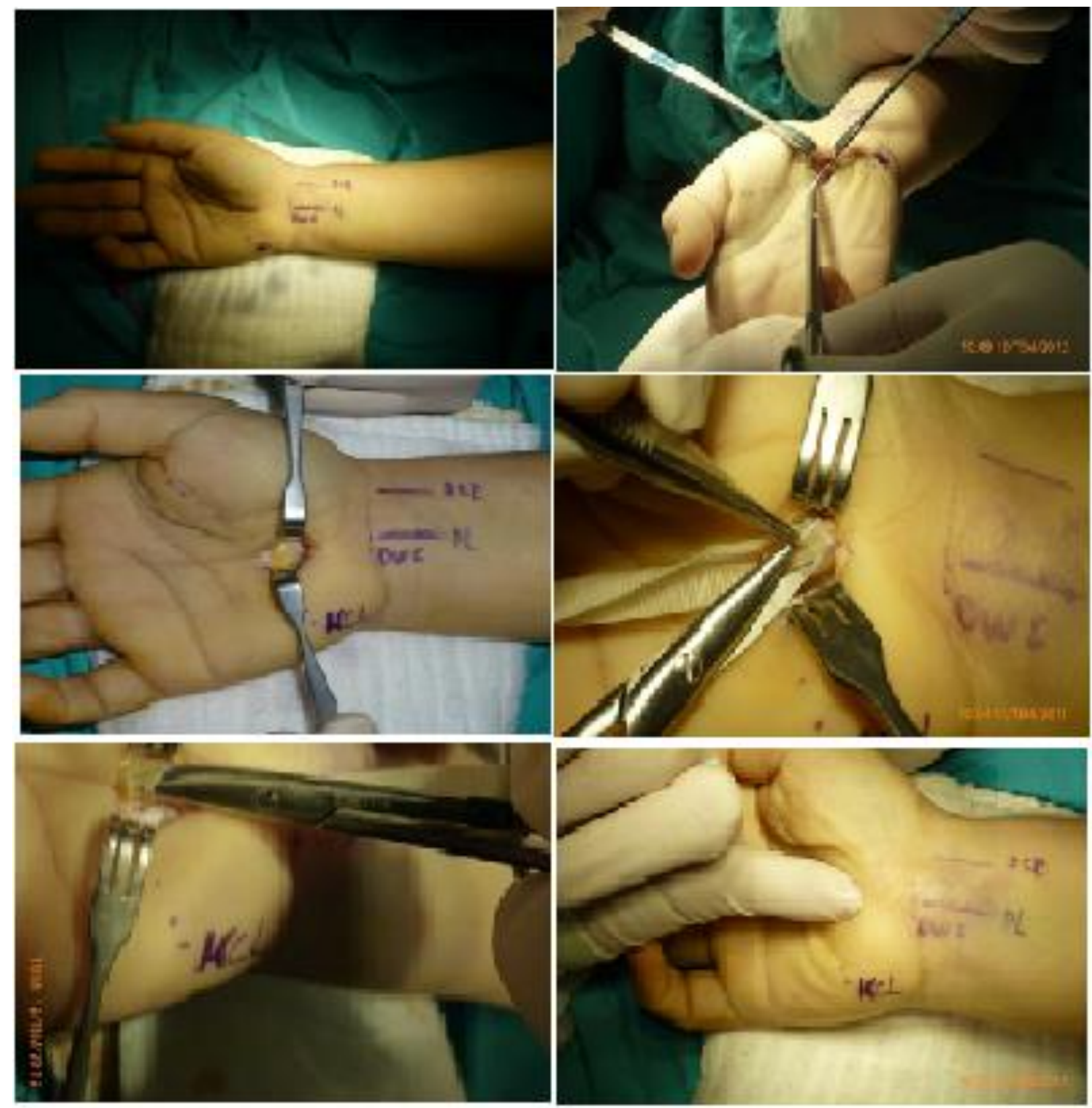

Şekil 1. Cerrahi teknik

adet penrose dren yerleştirildi ve cilt altı ile cilt dokuları uygun şekilde kapatıldı. Pansumanı takiben el atele alindi.

\section{Bulgular ve Tartışma}

3.1.Bulgular

Hastalar 6. ile 9. postoperatif aylarda telefonla aranarak kontrole çağrıldı, Araştırmaya 40 kişilik örneklem ile

başlanmış olup süreçte 4 kişiye ulaşılamadı ve 1 kişinin hayatını kaybettiği öğrenildi. Araştırmamıza 35 kişi ile devam edildi. Takiplerimize düzenli olarak devam eden hasta sayıs 35 idi. Hastalar en az 13 ay, en fazla 36 ay ve ortalama 24 ay takip edildi (Tablo 1). Bu süreçte hastalık nüksü görülmedi.

Tablo 1. Hastaların Yaş Ortalaması ve Takip Süre Ortalaması

\begin{tabular}{|l|c|c|}
\hline Değişken & $\mathrm{n}$ & ort \\
\hline Yaş & 35 & $51 \pm 7$ yaş \\
\hline Takip süresi & $13-36$ ay & 24 ay \\
\hline
\end{tabular}


Hastalarımızın rutin takiplerinde; muayeneleri yapıld1, Tinel, Phalen testleri değerlendirildi. Cerrahi insizyon yerinin ağrılı olup olmadığı sorgulandı ve muayene edilerek kontrol edildi. Hiçbir hastada aşırı duyarlılık, hipertrofik skar yada ağrı şikayeti olmadığı ortaya çıktı. Memnuniyet sorgulaması yapıldı, 1 hasta hariç (hastanın elindeki şikayetler azalmış, fakat tamamıyla iyileşmediğini ifade etmesi üzerine memnun olmadığ1 kabul edildi) tüm hastalarda memnuniyet sağlanmış olduğu öğrenildi. Literatürde endoskopik ve sınırlı insizyon tekniklerinin, yüzeyel palmar ark yaralanmasına sebep olduğu bilgisinden yola çıkarak, 35 hastadan random olarak seçilen 5 hastaya postoperatif takip süreçlerinde, palmar ark USG tetkiki yapılarak arkın derinliği ve patensi görüldü. Hastaların postoperatif dönemde rutin olarak EMG değerlendirilmesi yapıldı.

Tablo 2. Quick DASH-T ölçeğinin 1. ve 2. modullerinin preop ve postop dönemdeki ilişkinin belirlenmesi

\begin{tabular}{|l|r|r|r|c|}
\hline & Median & Minimum & Maximum & $p$ \\
\hline PREOP 1 & $\underline{70,45}$ & $\underline{29,54}$ & $\underline{100,00}$ & \\
POSTOP1 & $\underline{\underline{700}}$ & $\underline{, 00}$ & $\underline{75,00}$ & $<0,001$ \\
PREOP 2 & $\underline{75,00}$ & $\underline{43,75}$ & $\underline{100,00}$ & \\
POSTOP2 & $\underline{, 00}$ & $\underline{, 00}$ & $\underline{100,00}$ & $<0,001$ \\
\hline
\end{tabular}

Tablo 2'e göre, Quick DASH-T ölçeğinin preop ve postop değerleri arasında istatistiksel bir ilişki olup olmadığının test edildiği Wilcoxon testi sonucunda, Quick DASH-T ölçeğininpre op ve post op değerleri arasında istatistiksel olarak anlamlı ilişki olduğu belirlendi $(\mathrm{p}<0,001)$.

Tablo 3. BKTSA'nın duyu modülünün preop ve postop istatistiksel ilişkisinin belirlenmesi

\begin{tabular}{|c|r|r|r|r|}
\hline \multirow{2}{*}{} & \multicolumn{4}{|c|}{ Semptom şiddet skalas1 } \\
\cline { 2 - 5 } & Median & $\begin{array}{c}\text { Minimu } \\
\mathrm{m}\end{array}$ & $\begin{array}{c}\text { Maxim } \\
\text { um }\end{array}$ & $\underline{\mathrm{P}}$ \\
\hline Preop & $\underline{3,72}$ & $\underline{1,90}$ & $\underline{5,00}$ & \\
Postop & $\underline{1,00}$ & $\underline{1,00}$ & $\underline{4,00}$ & $\underline{<0,001}$ \\
\hline
\end{tabular}

Tablo 3'e göre yapılan istatistiksel analiz sonrası, BKTSA'nın preoperatif ve postoperatif duyu modülü değerlerinde istatistiksel olarak anlamlı bulundu $(\mathrm{p}<0,001)$.
Tablo 4. BKTSA'nın motor modulunun preoperative ve postoperatif istatistiksel fark1

\begin{tabular}{|c|r|r|r|r|}
\hline & \multicolumn{4}{|c|}{ Fonksiyonel durum skalas1 } \\
\cline { 2 - 5 } & $\begin{array}{c}\text { Media } \\
\mathrm{n}\end{array}$ & Minimum & $\begin{array}{c}\text { Maximu } \\
\mathrm{m}\end{array}$ & $\underline{\mathrm{P}}$ \\
\hline Preop & $\underline{3,62}$ & $\underline{1,25}$ & $\underline{5,00}$ & \\
Postop & $\underline{1,00}$ & $\underline{1,00}$ & $\underline{4,00}$ & $\underline{\leq 0,001}$ \\
\hline
\end{tabular}

Tablo 4'e göre, Yapılan istatistiksel analiz sonucunda BKTSA'nın preoperatif ve postoperatif motor modülü değerlerinde istatistiksel olarak anlamlı olduğu belirlendi $(\mathrm{p}<0,001)$.

Tablo 5. Tinel ve Phalen preop ve postop yüzdeleri

\begin{tabular}{|l|l|l|}
\hline TINEL & VAR & YOK \\
\hline PREOPRATIF & $31(\% 88,57)$ & $4(\% 11,43)$ \\
\hline POSTOPERATIF & $5(\% 14,28)$ & $30(\% 85,71)$ \\
\hline PHALEN & & \\
\hline PREOPERATIF & $32(\% 91,43)$ & $3(\% 8,57)$ \\
\hline PARTOPERATIF & $1(\% 2,86)$ & $34(\% 97,14)$ \\
\hline & & \\
\hline & & \\
\hline & & \\
\hline
\end{tabular}

Tablo 5'e göre, Tinel ve Phalen bulguları pre op-post op sayı frekansları verildi, Tinel bulgusu post op \%85,71 hastada negatif bulunurken, Phalen bulgusu ise post op $\% 97,14$ hastada negatif saptand. Tinel ve Phalen bulgularının post op dönemde yüksek oranda gerilemesi hastalığın ve bulgularının net olarak gerilediği anlamı taşımaktadır, yani hastalarda iyileşme görüldü.

Bland sınıflamasının Evre 2, 3 ve 4 çalıșmaya dahil edilmiş olup, evre 0-1-5-6 çalışma dişı tutuldu (Tablo 6). 
Tablo 6. Bland Siniflaması

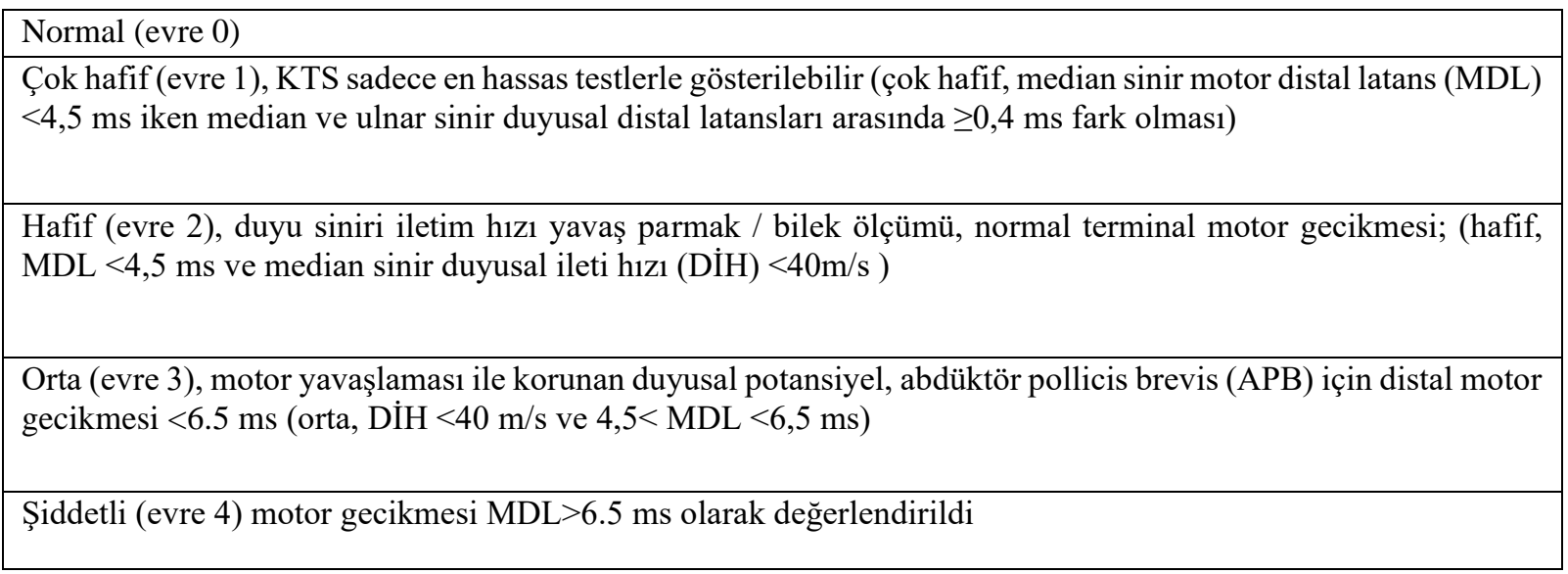

Tablo 7. Random seçilmiş hastaların preoperative ve postoperative EMG değerlendirmeleri

\begin{tabular}{|c|c|c|}
\hline Hasta Adı Soyadı & Preoperatif & Postoperatif \\
\hline $\begin{array}{l}\text { 1. } 8 \text { nolu hasta } \\
\qquad \begin{array}{r}\text { Sağ el KTS } \\
(\text { evre 3) }\end{array}\end{array}$ & $\begin{array}{l}\text { İki yanlı duyusal ve motor } \\
\text { bilek kanalı sendromu. } \\
\text { (2010) }\end{array}$ & $\begin{array}{l}\text { Duyusal ve motor bilek kanalı } \\
\text { sendromu var, ama düzelme saptandı. Sağ } \\
\text { median sinir duyusal cevap alınabilir olmuş } \\
\text { fakat yavaştı. Median sinir motor dalın } \\
\text { distal cevapları kısaldı, yani ileti hızlandı } \\
\text { (2012) }\end{array}$ \\
\hline $\begin{array}{l}\text { 2. } 13 \text { nolu hasta } \\
\qquad \begin{array}{r}\text { Sağ el KTS } \\
\text { (evre 4) }\end{array}\end{array}$ & $\begin{array}{l}\text { Sağda duyusal ve motor, } \\
\text { solda duysal bilek kanalı } \\
\text { sendromu(2010) }\end{array}$ & $\begin{array}{l}\text { Sağda motor tutulum düzeldi, } \\
\text { duyusal tutulum hafifledi, solda duysal } \\
\text { etkilenme minimal düzeldi (2012) }\end{array}$ \\
\hline $\begin{array}{r}\text { 3. } 38 \text { nolu hasta } \\
\text { Săg el KTS } \\
\text { (evre 4) }\end{array}$ & $\begin{array}{l}\text { İki yanlı duyusal ve motor } \\
\text { bilek kanalı sendromu. } \\
\text { (2011) }\end{array}$ & $\begin{array}{l}\text { Sağ taraf anlamlı değişiklik yoktu , } \\
\text { biraz daha kötüye gittiği belirlendi. Sol taraf } \\
\text { duyusal düzelme vardı. (2012) }\end{array}$ \\
\hline
\end{tabular}

Tablo 7‘ye göre; elektrofizyolojik hasta değerlendirilmesi preoperatif ve postoperatif EMG çektirilerek tüm hastalarda yapıldı. Postoperatif dönemde çekilen EMG bulgularında hastalarımızda anlamlı takip bulguları elde edilemedi. Literatür taramasında İyigün ve ark. (1988) preoperatif ve postoperatif her ne kadar klinik iyileşme olsa da, EMG 'de bu bulguların çok geç geldiğini ve hatta kimi vakalarda eski EMG değerlerinde kaldığını gösterdiler, dolayısıyla bu takibin istatistiksel anlam taşımadığını vurguladılar. Bir diğer çalışmada zaten yavaş düzelebilen EMG bulgularının ileri yaşlardaki hastalarda yaşla gelen ek hastalıklarının (diyabet, renal yetmezlik, tiroid hastalıkları vs.) etkisiyle daha da yavaş düzelme gösterdiğini ve buna rağmen yine ameliyat edilmeleri önerildi [2].

Randomize şeçilmiş hastalardan birinin postoperatif yüzeyel palmar ark USG değerlendirmesi sunuldu. Hastalarımız arasından random seçilen hastanın yüzeyel palmar arkları incelendi, arterlerin patensleri mevcut olduğu görüldü. Yüzeyel arkların derinliği ölçüldü (Şekil 2). 

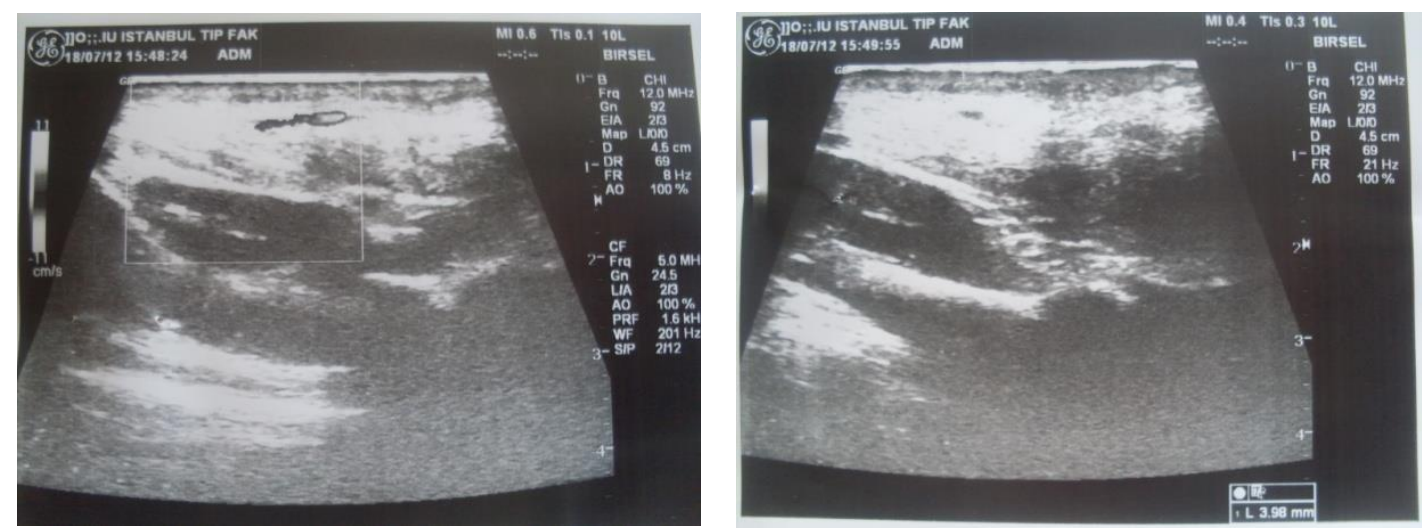

Şekil 2. Sağ el yüzeyel palmar ark; arter patensi (+), derinliği 3,98 mm

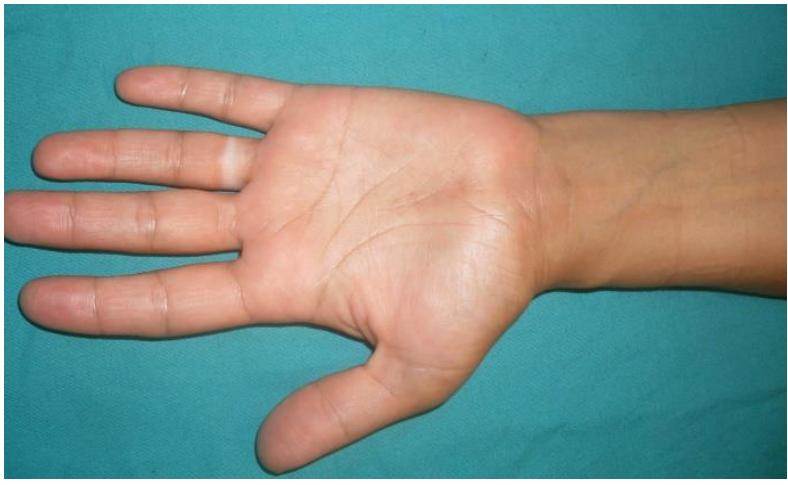

Şekil 3. Postoperatif görüntü 18 ay (Hasta No:5) ; pilar bölgede postoperatif nedbenin olmaması, hastaya avantaj sağlamaktadır

\subsection{Tartı̧̧ma}

Karpal tünel sendromu, sinirin karpal tünelde basiya uğraması sonucu gelişir. Bu bası sonrası mekanik olarak median sinir hasar görür, ayrıca zamanla iskemi nedeniyle de median sinir geri dönüşümsüz zarar görebilir. Deneysel çalışmalar basınç miktarı ve süresi arttıkça sinirin fonksiyonel bozulmasının da artacağını göstermektedir. Median sinir tekrarlayıcı mekanik strese maruz kaldığında demiyelinizasyon gelişmektedir, zamanla kan sinir bariyerinde bozulma ve aksonal hasar meydana gelir. Bası uzun sürdüğünde hasar geri dönüşümsüz olabilir.

Literatürde cerrahi tedavi için açık, sınırlı açık ve endoskopik kapalı yöntemler tarif edildi ve bu yöntemler karşılaştırıldı $[4,5,6]$.

1924 y1lında Galloway'ın karpal tünel cerrahisini gerçekleştirdiğinden bu yana bir çok cerrah farklı cerrahi insizyonlar üzerinde çalışarak daha sorunsuz bir cerrahi yöntem arayışında bulundular. Endoskopik (kapalı) karpal tunel cerrahisinin cerrahi tedavi uygulamaları arasına girdiği 1989 yılına kadar, klasik (açık) karpal tünel cerrahisi tek tedavi seçeneği oldu. Günümüzde karpal tünel cerrahi tedavisi 3 farklı yöntem ile uygulanmaktadır: Klasik (açık) karpal tünel teknik, halen altın standart cerrahi seçenek olarak kullanılmakta, bununla birlikte endoskopik karpal tünel ve sınırlı insizyonlar uygulanarak gerçekleştirilen karpal tünel gevşetilmesi teknikleri de uygun olgularda klasik yönteme alternatif olarak tercih edilebilmektedir. Standart insizyonlardan sonra hastaların yaşadıkları el bilek ağrıları, palmar bölge hassasiyeti gibi subjektif şikayetler farklı teknikler arayışına doğru cerrahları itti. $\mathrm{Bu}$ nedenle, 1989 yılında Okutsu ve Chow endoskopik tekniği tanımladılar [6]. Teknik uzun öğrenme eğrisi, yetersiz dekompresyona bağlı nüksler, yaşanabilecek sinir yaralanmaları ve maliyet yüksekliği nedeniyle çok yaygın kullanım sahası bulamadı $[7,8,9]$.

Klasik karpal tünel gevşetilmesi ameliyatlarında, tenar ve hipotenar bölgeler arasında oluşturulan uzun bir cerrahi insizyon kullanılarak girilip, ön kol distalinde ve karpal kanal içinde bulunan median sinir ortaya konarak serbestleştirmek mümkündür. Geniş disseksiyon cerrahi bölge içindeki tüm anatomik yapıları görerek her türlü işlemi gerçekleştirmeyi mümkün kılmaktadır (karpal tünel içi lezyon eksizyonunu; ganglion kisti, tendon tümörü, sinovyektomi, median sinirin eksternal nörölizi). Postoperatif dönemde, cerrahi yaranın iyileşmesinin uzun sürmesi, pilar bölge ağrısı ve hassasiyeti, sert nedbe oluşması, işe geri dönme süresinin uzaması ve bow string oluşması tekniğin zayıf yönlerini oluşturmaktadır [8].

Standart insizyonla sınırlı insizyonları karşılaştıran çalışmalarda her iki teknikte de yeterli dekompresyon sağlandığını, fonksiyonel ve semptomatik iyileşme açısından etkili olduğu belirlenmiştir. Tekniklerde farkı oluşturanın hızlı yara yeri iyileşmesi, hızlı fonksiyonel geri dönüş yara yeri ve pillar bölgede oluşan ağrı duyusu farklılıklarıdır [10,11]. Sonuçta standart insizyonun morbidite oranlarının yüksekliği endoskopik tekniklerin ise çok az cerrah tarafından etkili olarak uygulanır olabilmesi, sınırlı insizyonları popüler hale getirdi. Bizim çalışmamızda da iyileşmenin hızı ve kalitesi 
literatür ile benzer özelliktedir. Masa başı çalışan hastalarda pillar bölgesinin distal bilek krizin 1,5 cm'lik alanın masa ile temas ettiği gözlenmiştir ve bu bölgenin korunması skarların daha distalde yerleştirilmesi özellikle bu hasta grubunda postoperatif dönemde daha komforlu çalışma hayatı sunmaktadır.

Çalışmamızda postoperatif dönemde ağrı şikayetinin azaldığı saptandı. Das ve Brown 170 olguluk mini insizyon kullanılarak yapılan karpal tünel sendromu cerrahi serisinde, operasyon sonrası hastalarda skar dokusuna bağlı ağrı ve fleksör tendon yapışıklığına rastlamadıklarını bildirdi [12].

Karakurum ve ark. çalışmasında ise, sınırlı palmar insizyonda \%91 oranında etkili sonuçlar aldıklarını belirttiler $[13,14,15]$.

Şavk ve ark. çalışmasında; 24 olgu 2 gruba ayrıldı. Birinci grup standart insizyon, ikinci grup ise sınırlı distal insizyonla opere edildi. Sinırlı insizyon yapmanın az doku harabiyeti oluşturup skar dokusu ağrısını azalttığg ve fleksör tendonda gerginliği azalttığını belirttiler. Ancak, sınırlı insizyon tekniğinin dekompresyonda yetersiz kalabileceği ve sinir hasarı riskini artırabileceğini göz önünde tutmak gerektiğini belirttiler [14].

Balkarlı ve ark. serisinde ise sınırlı palmar insizyon orta palmar bölgeye yapılmış cerrahi uygulanan 74 eli değerlendirerek, sınırlı insizyon cerrahisinin etkili, ucuz ve kolay uygulanabilir olduğunu belirttiler [16]. Sınırlı insizyonlarda ortalama kesi boyu 1,5- $2 \mathrm{~cm}$ arasinda değişmektedir. Kesinin küçük olması yetersiz dekompresyona, sinir zedelenmesine, kanama kontrolü zorluğuna neden olabilir. Cerrahi için mini ekartörler gerekebilmektedir. Görüş alanı kısıtlılı̆̆ı nedeniyle olgularda operasyon mikroskobundan yararlanmak cerrahi süresini bir miktar artırsa da etkili görüş açısı ile olası sinir yaralanmalarını engelleyebilir. İyi bir ekartmanla standart insizyonla sağlananabilecek ölçüde yeterli ekspojur ve median sinirin karpal tünelde tamamen dekompresyonu sağlanabilir. Çalışmamızda da literatürü destekleyen sonuçlar bulundu.

Çalışmamızda sunulan, 2,5 cm'lik sınırlı insizyon uygulanılarak yapılan karpal tünel cerrahisi olgularımızda, klasik karpal tünel cerrahisinde uygulanan işlemler gerçekleştirildi. Palmar bölgedeki insizyon, yüzeyel palmar arkı disseksiyon esnasında görülebilir ve korunabilir k1lmaktadır. Fleksör retinakulum distalinden yapılmaya başlayan gevşetme median sinirin künt disseksiyonla korunmasını sağlamaktadır. Fleksör retinakulumun hemen üzerinden makasla yapılan disseksiyon ile cilt altı dokusu ve ligaman ayrıştırılarak net görüş imkanı sağlanmaktadır. Ligaman el hafif ekstansiyondayken sinir görülerek kontrollu şekilde kesilmektedir. Cerrah sol el serçe parmağıyla insizyondan girerek kolaylıka fleksör retinakulum ve antebrakiyal fasyanın tam olarak gevşetilip gevşetilmediğini kontrol edebilmektedir. Wright ve ark. kadavra çalışmalarında omuz, dirsek ve parmak hareketlerine bağlı olarak median sinirin karpal tünel içine 19,6 mm kadar kayarak girebildiğini gösterdiler. Bu çalışmada disseksiyon sırasındaki median sinirin askılanmasıyla hafif traksiyon altında $2 \mathrm{~cm}$ 'e yakın bir segmentin distale doğru kayma yapabildiği gösterildi. $\mathrm{Bu}$ durum median sinire eksternal nöroliz yapabilme imkanı sağlar. Bununla beraber, insizyon hattından median sinir rekürran dalı disseke edilerek nöroliz yapılabilmektedir. Median sinirin radial tarafa ekarte edilmesi ile derin fleksör loj ve karpal tünel tabanı kolaylıkla serçe parmakla kontrol edilmektedir. Son olarak, sinovyal hipertrofinin mevcut olduğu olgularda belirli ölçüde sinovyektomi yapılabilmektedir $[17,18,19]$.

Çalışmamızda olguların postoperatif değerlendirmesinde, Tinel bulgusu \%85,7 hastada negatif, Phalen bulgusu ise \%97,1 hastada negatif bulundu. Yapılan endoskopik median sinir serbestleştirilmesi araştırmalarında, Tinel bulgusunun postoperatif dönemde negatifliği \%92,5 ve Phalen bulgusunun negatifliği \%97,2 olarak verilmektedir. Çalışmamızda Tinel bulgusunun negatifliği literatür verilerine göre yaklaşık $\% 7$ daha az olarak değerlendirilirken, Phalen bulgusu literatür bulguları ile paralellik göstermektedir [20]. Bu oranların farklılık göstermesinin vaka sayısının 40 ile sinırlı olması ile açıkland1.

Araştırmamızda, elektrofizyolojik hasta değerlendirilmesi preoperatif ve postoperatif EMG çektirilerek tüm hastalarda yapıldı. Çalışmamızda postoperatif yakın dönemde (6. ayda) çekilen EMG bulgularında anlamlı ve hızlı düzelme bulguları saptanmadi. Literatür taramasında İyigün ve ark. (1988) preoperatif ve postoperatif her ne kadar klinik iyileşme olsa da EMG 'de bu bulguların çok geç geldiğini ve hatta kimi vakalarda eski EMG değerlerine kaldığını göstermişlerdir, dolayısıyla bu takibin istatistiksel anlam taşımadığını vurgulamışlardır. Bir diğer çalışmada zaten yavaş düzelebilen EMG bulgularının ileri yaşlardaki hastalarda yaşla gelen ek hastalıklarının (diyabet, renal yetmezlik, tiroid hastalıkları vs.) etkisiyle daha da yavaş normalleştiği ve buna rağmen yine de ameliyat edilmeleri önerilmektedir [18,21].

Çalışmamızda Bland sınıflamasının Evre 2, 3 ve 4 çalışmaya dahil edilmiş olup, evre 0-1-5-6 çalışma dışı tutuldu. Bland sınıflaması; normal (evre 0); Çok hafif (evre 1),KTS sadece en hassas testlerle gösterilebilir (çok hafif, median sinir motor distal latans (MDL) $<4,5 \mathrm{~ms}$ iken median ve ulnar sinir duyusal distal latansları 
arasında $\geq 0,4$ ms fark olması); Hafif (evre 2), duyu siniri iletim hızı yavaş parmak / bilek ölçümü, normal terminal motor gecikmesi; (hafif, MDL <4,5 ms ve median sinir duyusal ileti hızı (DİH) $<40 \mathrm{~m} / \mathrm{s}$ ); Orta (evre 3), motor yavaşlaması ile korunan duyusal potansiyel, abdüktör pollicis brevis (APB) için distal motor gecikmesi $<6.5 \mathrm{~ms}$ (orta, DİH $<40 \mathrm{~m} / \mathrm{s}$ ve 4,5< $\mathrm{MDL}<6,5 \mathrm{~ms}$ ); Şiddetli (evre 4) motor gecikmesi MDL $>6.5 \mathrm{~ms}$ olarak değerlendirildi (Tablo 6). Başka bir araştırmaya göre Hafif KTS: Median duysal yanıt distal latansı ile ulnar duysal yanit distal latansı arasındaki farkın $>1$ msn olması veya 4. parmak kayıtlı medyan-ulnar sinir tepe latansları arasındaki farkın $>0.5$ msn olması Orta KTS: Yukarıdakilere ek olarak median motor sinirin distal latansının uzaması (>4.0 msn) Ağır KTS: Sıklıkla duysal potansiyel amplitüd düşüklüğü/yokluğu ve motor yanıt amplitüdünün düşmesi ( 5.5 msn) [20].

Karpal tünel sendromu ve EMG bulguları arasındaki ilişkiyi açıklamaya çalışan bir çalışmada, şikayeti devam eden hastaların median motor latans ortalaması $6,63 \mathrm{msn}$ ( $\min 3,04-\max 11,04)$, ileti hızı ise ortalama $42,91 \mathrm{~m} / \mathrm{sn}$ (min 36,88 - $\max 51,8)$ idi. Hiçbir şikayeti olmayan hastaların median motor latans ortalamas $4,32 \mathrm{msn}$ (min 2.9 - max 5.6), median motor hızı ortalamasının 53,1 m/sn (min 45 - $\max 58.7 \mathrm{~m} / \mathrm{sn}$ ) olduğunu gördüler. Hastaların 86'sında ameliyat öncesi yapılmış olan elektrofizyolojik incelemelerinde median sinir duyu iletimi elde edilemedi. Şikayetleri devam eden hastaların 16'sinda median sinir duyu potansiyeli, 2'sinde hem duyu hem motor potansiyeli elde edilemedi. Şikayeti olmayan hastaların ise 70'inde median sinir duyu iletimi elde edilemezken, tamaminda motor potansiyel elde edilemedi. Hastaların karpal tünel sendromu nedeniyle konservatif tedavi aldığı dönemdeki iş güç kayb1 ortalama 17 gün (10-23) iken, cerrahi sonrası ortalama işe başlama zamanı 12 gün (8-16) olduğu gösterildi [22]. Literatür ile araştırmamız arasında benzer bulgular tespit edildi..

\section{Sonuç}

Kliniğimizde standart cerrahi tedavi yöntemi olarak klasik açık teknik, karpal tünel cerrahisi uygulanmaktadır. Sinırlı insizyon tekniğinin diğer cerrahi tekniklere göre avantaj ve dezavantajlarının daha objektif verilerle ortaya konabilmesi için karşılaştırmalı klinik çalışmaların yapılması gerektiği aşikârdır. Ancak, literatür bilgileri ve bu çalışmamızdan elde edilen subjektif ve objektif sonuçlar, 2,5 cm'lik sınırlı insizyonlu açık karpal tünel cerrahisinin seçilmiş olgularda yeterli görüş alanı ve disseksiyon imkanı sunmaktadır ve tercih edilebilir bir cerrahi yöntem olabileceğini vurgulamaktadır. Özellikle elini daha fazla kullanmak zorunda olan kişilerde sınırlı insizyon ile yapılan cerrahi tavsiye edilmektedir. Bu teknik ile bu tip hastalar; erken işe dönme, ağrının azalması ve elini postop dönemde daha kısa sürede aktif kullanabilmeleri açısından avantajlıdır.

\section{References}

1. Bland, J.D, A neurophysiological grading scale for carpal tunnel syndrome. Muscle Nerve, 2000, 23 (8), 1280-3.

2. İyigün, Ö, Rakunt, C, Çelik, F, Şahin, C, Preoperative and postoperative evaluation of patients with carpal tunnel syndrome, 19 May University Medical Faculty Journal, 1988, 5(2), 163-172.

3. Szabo, R.M, Entrapment and compression neuropathies. In: Green DP, Hotchkii RN, Pederson WC, editors. Green's Operative Surgery, New York etc: Churchill Livingstone, 1999, Vol 2. 4 ed, 1404-1447.

4. Ziyal, Y.M, Döşoğlu, M, Duman, H, Öztürk, A, Gezen, F, Karpal tünel sendromu: 36 olgunun (50 el) cerrahi sonuçlarının literatür ile karşılaştırılması, AYBÜ Düzce Tip Fakültesi Dergisi, 1999, 1, 55-62.

5. Mondelli, M, Padua, L, Reale, F, Carpal tunnel syndrome in elderly patients: results of surgical decompression, Journal of Peripheral Nerve Syst, 2004, 9(3), 168-176.

6. Cokluk, C, Senel, A, Iyigün, O, Celik, F, Rakunt, C, Open median nerve release using double mini skin incision in patients with carpal tunnel syndrome: technique and clinical results, Neurologia medicochirurgica, 2003, 43(9), 465-468.

7. Tetik, B, Erol, B, Comparison of alternative methods used in the surgical treatment of carpal tunnel syndrome, Journal of Arthroplasty \& Arthrosopic Surgery, 2002, 13 (1), 5-9.

8. Cellocco, P, Rossi, C, Bizzarri, F, Patrizio, L, Costanzo, G, Mini-open blind procedure versus limited open technique for carpal tunnel release: a 30-month follow-up study, Journal of Hand Surgery, 2005, 30 (3), 493-499.

9. Hankins, C.L, Brown, M.G, Lopez, R.A, Lee, A.K, Dang, J, Harper, R,D, A 12-year experience using the Brown two-portal endoscopic procedure of transverse carpal ligament release in 14,722 patients: defining a new paradigm in the treatment of carpal tunnel syndrome. Plastic Reconstructive Surgery, 2007, 120(7), 1911-1921.

10. Chen, Y.T, L, Williams, M. J, Fredericso, M, Review of ultrasonography in the diagnosis of carpal tunnel syndrome and a proposed scanning protocol, Journal of Ultrasound in Medicine, 2016, 35, 11, 2311-2324.

11. Da Silva, M.F, Single portal endoscopic carpal tunnel release, Tech orthopaedics, 2006, 21, 35-41.

12. Serra, J.M, Benito, J.R, Monner, J, Carpal tunnel release with short incision, Plastic and Reconstructive Surgery, 1997, 99 (1), 129-135.

13. Wongsiri, S, Liawrungrueang, W, Minimally Invasive Carpal Tunnel Release (CTR) Using the Wongsiri Technique with MiniSURE, Hindawi Advances in Orthopedics. 2020, Article ID 6273723, 6 pag. 
14. Şavk, Ö, Turgut, M, Çullu, E, Akyol, A, Alpraslan, B, Comparison of standard and mini-incision techniques in surgical decompression of carpal tunnel syndrome, ADÜ Faculty of Medicine Journal, 2002, 3 (2), 9 - 13.

15. Karakurum, G, Güleç, A, Kalender, M, Loosening the carpal tunnel with a mini palmar incision that does not exceed the batteries, Ege R (ed), XVI. National Turkish Orthopedics and Traumatology Congress Book, Ankara: Sargın Offset, 1999, 488-489.

16. Balkarlı, H, Öztürk, I, Çakıcı, İ, Our surgical treatment results in the carpal tunnel syndrome with a mini incision from the middle palmar region, Hand and Microsurgery, 2012, 1(3), 79-83.

17. Yüce, İ, Kahyaoğlu, O, Çavuşoğlu, H, Aydın, Y, Minimally Invasive Open Surgical Approach and Outcomes for Carpal Tunnel Syndrome, Sisli Etfal Hastan Tip Bul, 2019, 53 (3), 247-251.

18. Wright, T.W, Glowczewskie, F, Wheeler, D, Miller, G, Cowin, D, Excursion and strain of the median nerve, $J$ Bone Joint Surgery, 1996, 78 (12), 1897-1903.

19. Chow, J.C, Hantes, M.E, Endoscopic carpal tunnel release: thirteen years' experience with the Chow technique, Journal of Hand Surgery.2002, 27 (6), 1011-1018.

20. Ghaly, B, Ghaly, S, The Use of Neuromuscular Ultrasound and NCS/EMG Testing in the Differential Diagnosis of Carpal Tunnel Syndrome and Radiculopathy. Neurodiagnostic Journal, 2019, 59 (1), 23-33.

21. Tunç, A, Doğan Güngen, B, Karpal Tünel Sendromu Hastalarında Elektrodiagnostik Evreleme ile Klinik Evre, Semptom Süresi ve Vücut Kitle İndeksi Arasındaki İlişkinin Değerlendirilmesi, Dicle Medical Journal, 2017, 44 (2) , 159-166.

22. İnce, B, Baycar, Z, Çolak, T.S, Uyar, M, Dadacı, M, Koruyucu, I.H, The role of EMG in the timing of carpal tunnel syndrome surgery, Selcuk Medical Journal. 2019, $\quad 35 \quad$ (2), 147-53.

http://edergi.cbu.edu.tr/ojs/index.php/cbusbed isimli yazarın CBU-SBED başlıklı eseri bu Creative Commons Alınt1-Gayriticari4.0 Uluslararası Lisansı ile lisanslanmıştır. 